\title{
TRADUÇÃO TEATRAL E CÓDIGOS EXPRESSIVOS ${ }^{1}$
}

\author{
Barbara Delli Castell ${ }^{1}$ \\ 11Università “Gabriele D’Annunzio” Chieti-Pescara, Itália
}

Tradução de Maria Fernanda Gárbero de Aragão²

${ }_{2}^{2}$ Universidade Federal Rural do Rio de Janeiro, Nova Iguaçu, Rio de Janeiro,

Brasil

\begin{abstract}
Resumo: Este artigo analisa algumas complexidades encontradas na tradução de textos teatrais, propondo um histórico das teorias que discutiram o tema. A partir do conceito de "performatividade" serão discutidos procedimentos que norteiam o tradutor de um texto que, embora escrito, é destinado à representação, diferenciando, assim, o texto cênico do dramático. O palco, ao ser tratado como um espaço de finalidade, bem como os atores e o público, como fundamentais à compreensão do texto dramático, aponta considerações que, na experiência de tradução, se fazem presentes no contexto em que o texto traduzido será encenado.
\end{abstract}

Palavras-chave: Tradução Teatral; Texto Cênico; Performatividade

\section{THEATER TRANSLATION AND EXPRESSIVE CODE}

\begin{abstract}
This article analyzes some complexities found in the translation of theatrical texts, proposing a history of the theories that discussed the theme. From the concept of "performativity" will be discussed procedures that guide the translator of a text that, although written, is intended for representation, thus differentiating the scenic text from the dramatic. The
\end{abstract}

1 "Traduzione teatrale e codici espressivi". Texto publicado em Traduttologia, Bari, n. 2, 2006: 55-70. As notas presentes neste estudo correspondem ao seu original. A tradução foi autorizada pela autora Barbara Delli Castelli, a quem gentilmente agradeço. 
stage, when treated as a space of purpose, as well as the actors and the public, as fundamental to the understanding of the dramatic text, point out considerations that, in the translation experience, are present in the context in which the translated text will be staged.

Keywords: Theatrical Translation; Scenic Text; Performativity

A história do teatro nos conta que a língua em cena nem sempre esteve circunscrita somente à questão fônica do ator, mas à busca de contribuições de outras áreas do conhecimento, artes e emprego de técnicas das mais variadas. O teatro, por sua natureza, propõe uma arte polissêmica, cuja "língua global" alcança, desde a elaboração do texto, todo código expressivo possível: do visível ao sonoro, luminoso, rítmico, entre outros.

Ao se propor como modelo da comunicação humana, o teatro se difere de qualquer outro modelo de espetáculo, graças ao contato direto e imediato entre ator e espectador. Enquanto na comunicação verbal cotidiana existe um emissor que emite uma mensagem para se dirigir a um destinatário no âmbito de um determinado contexto, no teatro, por outro lado, a comunicação se dá por meio de signos: aqueles direcionados aos espectadores (receptores) pelos atores, pelo diretor, pelo autor da obra, pelo cenógrafo, etc (emissores), numa produção irrestrita de significados. O papel principal deste processo cabe ao ator, ao seu corpo e às suas palavras. Todos os movimentos do corpo e da face são geralmente signos cinésicos e, mais precisamente, os da face são signos mímicos; os movimentos do corpo, sem mudança de localização, gestuais; enquanto os movimentos no espaço são proxêmicos. Já os signos referentes à oralidade distinguem-se em linguísticos e paralinguísticos. Os linguísticos estão relacionados à palavra, ao seu significado; os paralinguísticos correspondem aos sons e à entonação. Os signos gestuais, mímicos, proxêmicos e paralinguísticos, ao contrário dos linguísticos, não têm significado rigorosamente determinado. Os signos mímicos adquirem significado quando estão presentes em expressões faciais "reconhecíveis" que mostram e / ou representam determinadas condições: alegria, tristeza, raiva, assombro, encan- 
tamento, entre outros. Os signos paralinguísticos, embora se enquadrem num esquema parecido, em nível de som e entonação, não têm um significado único. No que concerne aos signos gestuais, é possível afirmar que eles não têm significado para além do contexto em que são empregados.

Devido à sua complexidade, o texto teatral ficou por muito tempo deixado de lado pelas análises semiológicas que priorizavam, em geral, o texto literário. Apenas graças às atividades pioneiras de alguns teóricos da Escola de Praga $^{2}$ - os primeiros a se interessarem pela estrutura e pelos mecanismos linguísticos de produção de sentido e comunicação do teatro - percebeu-se que as análises dos signos portadores de significado poderiam se estender também a textos que ultrapassavam a página escrita, que se abriam ao mundo da representação, da performance ${ }^{3}$. Dessa afirmação provêm a ina-

2 Cabe ressaltar, numa primeira fase, sobretudo Otacar Zich (Estetika dramatického umění, Praga, Melantrich, 1931) e Mukarovsky, (An Attempted Structural Analysis for the Phenomena of the Actor, Praga, 1931), seguido por Veltrusky ("Dramatic Text as a Component of Theatre". Semiotics of Art: Prague School Contributions. L. Matejka, I.R. Titunik (Ed.) (1976): 94-117), Bogatyrëv ("Les signes du théâtre, Poétique, 8, (1971): 517-530) e Honzl ("La mobilité du signe théâtral”, Travail Théâtral, 4, (1971): 5-20).

${ }^{3}$ Otacar Zich afirma que o teatro consiste de sistemas heterogêneos e independentes, nenhum dos quais tem uma particular proeminência. É o primeiro dos semiólogos do teatro a negar uma predominância automática do texto escrito sobre os outros sistemas; ao contrário, entendendo-o como um dos sistemas que participam na constituição do teatro como representação dramática total. Por outro lado, aplicando a definição saussuriana de signo, Mukarovsky 3-9 observa que a obra artística reside na consciência coletiva do público e se identifica com a unidade semiótica na qual o significante é "a obra em si", e o significado é "o objeto estético". Para Mukarovsky, isso representa o primeiro passo para uma semiótica da performance, na qual o texto cênico se torna um macro-signo, cujo significado é constituído por seu efeito total. Esta perspectiva é importante para a semiótica teatral pelo menos por duas razões diferentes, mas extremamente correlatas: por uma parte, isso evidencia a subordinação de todos os elementos constitutivos à integralidade e a importância do público como criador de significado dessa integralidade (macro-signo), por outra, a performance não representa um signo isolado, mas uma rede de unidade semiótica pertencente a sistemas diferentes, porém cooperativos.

Cad. Trad., Florianópolis, v. 40, n⿳ 3, p. 300-319, set-dez, 2020. 
dequação de uma abordagem exclusivamente literária da semiótica e, progressivamente, um deslocamento do eixo de interesse, beneficiando o texto cênico em relação ao dramatúrgico ${ }^{4}$.

Com Kowzan ${ }^{5}$, no final dos anos sessenta, a semiótica do teatro nasce e se desenvolve como disciplina que objetiva elaborar uma codificação específica dos sistemas de signos e configurar sistemas exatos de análises. Kowzan formula a primeira distinção entre signos naturais e artificiais. Os signos naturais incluem aqueles fenômenos independentes da vontade humana (por exemplo, um relâmpago como sinal de um temporal, a febre para a doença, etc). Os signos artificiais, ao contrário, dependem da vontade humana de indicar ou comunicar alguma coisa a alguém. Essa oposição não é absoluta e permitiu que Kowzan formulasse um princípio posterior: a "artificialização" no palco de signos aparentemente naturais. O espetáculo transforma signos naturais em artificiais. Signos involuntários na vida se tornam voluntários no palco ${ }^{6}$.

${ }^{4}$ Essa distinção parece um tanto rígida se se considera, como Veltrusky, que há dramas destinados somente à leitura e não à representação. Um exemplo disso são as comédias de Alfieri ou as tragédias de Sêneca, ainda que, a respeito desse último, a questão seja controversa.

${ }^{5}$ Kowzan, T. "Le signe au théâtre: introduction à la sémiologie de l'art du spectacle”. Diogène, 61, (1968): 59-90; Kowzan, T. Littérature et spectacle. Berlim: The Haugue Mouton, 1975.

${ }^{6}$ Além de definir a ideia e a especificidade dos signos, Kowzan propõe um modelo para determinar as partes constitutivas do teatro, estabelecendo treze sistemas de signos como componentes básicos da performance. Esses sistemas identificam duas categorias principais de signos: os auditivos e os visíveis, que concernem ou não ao ator, e existem no tempo e no espaço. Tais signos estão presentes em cinco categorias: 1 . Signos auditivos que, como parte do texto verbal, dependem do ator e existem somente no tempo. São eles: palavras (sistema 1) e entonação (sistema 2); 2. Signos visíveis, classificados como "expressões do corpo", dependem do ator e existem tanto no tempo quanto no espaço. Tais signos são a mímica (sistema 3), a gestualidade (sistema 4) e o movimento (sistema 5); 3. Signos visíveis que, codificados como "aparência externa do ator", se referem ao ator, mas existem só no espaço; 4. Signos visíveis que, ditos "aparência do palco", são externos ao ator e existem tanto no tempo como no espaço. Tais signos são aparatos cênicos (sistema 9), cenários (sistema 10) e iluminação (sistema 11); 5. Signos auditivos que, nomeados de "sons desarticulados" (ou "efeitos sonoros não 
Contrários à concepção linguístico-estruturalista que considerava o teatro como uma linguagem, privilegiando o texto dramático, Mounin e Ruffini ${ }^{7}$ foram os primeiros a apontar uma chance de modificação radical da abordagem, assumindo o espetáculo concreto como verdadeiro objeto da análise semiótica ${ }^{8}$.

Nos últimos anos, foi necessário um novo olhar à revalorização do texto escrito, que não deixa de ser o primeiro produto que o autor entrega ao público. Como consequência disso, em toda a literatura mais recente sobre o assunto, tornou-se quase uma unanimidade inconteste a necessidade de não estabelecer qualquer prioridade entre texto dramatúrgico e texto cênico. Se de fato o primeiro, como se diz, é cronologicamente anterior ao segundo, isso está na potência da própria representação. Para "atualizar-se", para ser "completo", o texto dramatúrgico não pode, então, prescindir do cênico. Por sua vez, isso traz de volta o texto cênico, por meio daquilo que Ingarden ${ }^{9}$ chama de Nebentext, isto é, o texto que contém as stage directions, ao lado do Haupttext, isto é, o corpo principal do texto dramático. Além de uma função linguística, o texto assume uma função proairética, por criar a ação ${ }^{10}$.

Por outro lado, nem é preciso dizer que uma representação cênica pode ser mal concebida sem um texto por trás. Considerando certa reciprocidade nessa dependência entre os dois textos, a sin-

articulados"), podem ser independentes do ator e existem apenas no tempo. Esses signos são a música (sistema 12) e os efeitos sonoros (sistema 13).

${ }^{7}$ Mounin, G. Introduction à la sémiologie. Paris: Les Editions de Minuit, 1970.; Ruffini, F. "Semiotica del teatro: ricognizione degli studi", Biblioteca teatrale, 9, (1974): 34-81.

${ }^{8}$ Reflexões posteriores sobre a dimensão performativa do teatro se devem a Kirby (A Formalist Theatre. Filadélfia: University of Pennsylvania Press, 1987) e Elam (The Semiotics of Theatre and Drama. Londres: Methuen, 1980).

${ }^{9}$ Ingarden, R. The Literary Work of Art: An investigation on the Borderlines of Ontology, Logic and Theory of Literature. With an Appendix on the Functions of Language in the Theatre. Evanston III. Northwestern: Northwestern University Press, 1973, p. 208.

${ }^{10}$ Ver Bertozzi, R. "Francesca da Rimini: Semiotica e Testo Teatrale". Francesca da Rimini: Tragedia in cinque atti, edited by Paul Heyse, Milão: LED, 2003, pp. 49-68.

Cad. Trad., Florianópolis, v. 40, nº 3, p. 300-319, set-dez, 2020. 
gularidade do texto dramático com relação ao literário é clara; o primeiro, de fato, remete à dimensão mimética, e o segundo a uma diegética ${ }^{11}$. Embora essa intertextualidade seja agora uma aquisição teórica comum, na prática ainda há pouco diálogo entre semiólogos que desejam pesquisar a performance, ou mesmo o texto ${ }^{12}$.

Retornando a atenção ao discurso dramático do texto teatral, é preciso destacar de imediato que ele se dá sobre dois eixos de comunicação: tanto do ator-público, como da personagem-personagem.

A estrutura conceitual e cognitiva que rege a fruição teatral é dada pelo quadro, ou em termos emprestados da sociologia, pelo frame, no qual ator e espectador negociam a comunicação sígnica. O frame teatral é essencialmente distinguido por duas características: a pressuposição de que o público não tem o direito nem o dever de participar na ação desempenhada no palco e a aceitação da realidade teatral como fiction. A partir desses pressupostos, a semiose teatral é confiada aos indicadores dêiticos, que têm a função de evidenciar as relações de reciprocidade entre os atores e entre os atores e o público, regulando as articulações dos atos discursivos. Pressuposto para tal condição é a aceitação por parte do espectador do caráter mimético da ação cênica. Partindo deste ponto de vista, o frame poderia ser entendido como uma série geral de normas de tradução que permitem a passagem de um código ao outro.

O conceito preliminar para encarar o discurso dramático é, portanto, o contexto em que se atua, ou seja, a cena a que se refere através do uso da dêixis e da sua função de word-creating. Tratase de uma antiga dicotomia conceitual que, de distintas maneiras, continuamente está presente no cerne dos estudos linguísticos e semióticos, bem como nos estudos sociais e comunicativos, e contrapõe o texto ao contexto. O primeiro (de competência semiótica) seria um objeto autônomo com limites bem definidos, com um início, um desenvolvimento e um fim, e o segundo (de competência sociológica) seria um lugar das práticas sociais e dos usos reais

${ }^{11}$ Ibidem.

${ }^{12}$ Isso é lamentado por Elam (op. cit., 1980, VI cap.).

Cad. Trad., Florianópolis, v. 40, no 3, p. 300-319, set-dez, 2020. 
em que ele mesmo se concretiza, em que é produzido e fruído. Do ponto de vista semiótico, essa dicotomia não faz sentido, pois tudo isso que determina qualquer significação é, por princípio, objeto de análise semiótica. A superação da distinção entre texto e contexto leva, então, a considerar a noção de discurso. Um texto, seja ele de qualquer natureza, não se limita somente a transmitir um número restrito de conteúdos; internamente, o texto apresenta também uma imagem da situação comunicativa, do emissor e do destinatário e, dessa maneira, propõe regras práticas à sua fruição. Assim, o discurso é uma realidade social e textual, culturalmente definida e semioticamente articulada.

A dêixis, ou expressões indexais, concede uma função ativa à linguagem; sem isso não haveria o contexto, a cena e, ainda, o próprio drama. Graças à dêixis, o falante pode se voltar para aqueles elementos (animados ou inanimados) do contexto de enunciação, estejam eles presentes na cena ou como parte de mundos invisíveis, isto é, aqueles que o falante evoca ou sugere e que existem de alguma maneira na realidade cênica. A dêixis é integrada, frequentemente, pelo gesto. Um pronome demonstrativo, por exemplo, graças ao gesto - ou indicador cinésico especificador - permite que o objeto da dêixis seja "mostrado" 13 .

Mais do que na comunicação cotidiana, no gênero teatral, as mensagens são vinculadas por meio da modulação da voz, da gestualidade, da postura, e os atos comunicativos podem ser conotados para facilitar a compreensão da mensagem, ampliando a relação semiótica entre os diversos códigos e canais expressivos. Voz e gesto explicitam informações relativas à troca dialógica, aos vínculos entre personagens, ao enredo narrativo: substancialmente, representam um tipo de co-texto semiótico, cuja função é também alcançar o envolvimento do público.

${ }^{13}$ A definição de ostensione (demonstração) dada por Umberto Eco (Trattato di semiotica generale, Milão, Bompiani, 1975) e hoje aceita em geral, atinge o alvo da fundamental diferença entre texto literário e texto teatral. Na narrativa, por exemplo, pessoas, objetos e acontecimentos são descritos e contados. No teatro, vêm “ostentados”, mostrados.

Cad. Trad., Florianópolis, v. 40, n⿳0 3, p. 300-319, set-dez, 2020. 
Para o teatro, esses elementos precisam ser considerados numa estreita relação com o espaço cênico, espaço que representa o contexto "dentro do qual" e "com o qual" voz e gesto interagem, dando forma sígnica às diversas ações e semiotizando partes do próprio espaço. $\mathrm{O}$ estado emotivo de uma personagem, por exemplo, pode ser indicado graças à modificação cênica, expresso por meio de variações prosódicas específicas e explicitado pela gestualidade. As referências dêiticas presentes no texto necessitam, portanto, da realização cênica para sua desambiguação (seja pelos atores, seja pelos espectadores) ${ }^{14}$.

Junto ao aspecto dêitico, o discurso dramático acarreta a performance. No teatro, as ferramentas da língua são atos de fala com função proairética, ou seja, constituintes da ação. A teoria dos atos de fala, desenvolvida sobretudo pelos filósofos da linguagem, como Austin, Grice e Searle ${ }^{15}$, apresenta a seguinte classificação:

a. Atos locucionários: são atos de fala que produzem enunciados que façam sentido;

b. Atos ilocucionários: realizam-se quando há uma pergunta, uma ordem, a formulação de uma promessa, quando a verdade de uma proposição é afirmada ${ }^{16}$.

\footnotetext{
${ }^{14}$ Uma outra referência indicativa próxima da dêixis, mas de certa maneira oposta a ela, porque, ao invés de ter uma função exofórica, de world-creating, tem uma endofórica (voltada para o interior do texto e não para o co-texto externo) é a anáfora. Esta é diferente da dêixis porque, ao contrário de indicar diretamente um objeto, toma para si o referente da expressão antecedente. Por exemplo: “meu primo é médico. Ele vive na França". Com a dêixis, introduzimos pela primeira vez entidades no universo do discurso. A anáfora, por outra parte, pressupõe que tais entidades já existam. É claro, assim, que a anáfora reporta (função endofórica) diretamente ao texto mais do que ao contexto extra-linguístico, ou seja, para que entendamos ao que está fora da página.

${ }^{15}$ J. L. Austin, J. O. Urmson e M. Sbisà. (Eds.). How to Do Things with Words. Cambridge Mass: Harvard University Press, 1962; H. P. Grice, Logic and Conversation, William James Lectures. Harvard: Harvard University, 1967; Searle, J. Speech Acts: an Essay in the Philosophy of Language. Cambridge: Cambridge University Press, 1969.

${ }^{16}$ Searle (A Taxonomy of Illocutionary acts, Trier, Laut, 1976) apresenta uma classificação mais detalhada dos atos ilocucionários, distinguindo-os em: 1) as-
} 
c. Atos perlocucionários: indicam o fim ou o efeito realizado por meio do ato ilocucionário, como persuadir, irritar, etc.

Lembremos que, como num jogo de caixas chinesas, o ato perlocucionário inclui, por sua vez, o ato ilocucionário e o locucionário. Um exemplo são as fórmulas de apresentação ("Olá, o meu nome é Mário”) que se enquadram, assim, nos atos ilocucionários. Uma fórmula desse tipo é também um ato locucionário, porque constitui uma frase de sentido completo, mas de modo algum é um ato perlocucionário, uma vez que não chega a surtir efeito.

Por construírem efetivamente a ação, é necessário que os atos ilocucionários realizem o que Searle ${ }^{17}$ define como condições de felicidade:

a. Condições preparatórias: o falante deve ser autorizado a realizar um ato com base no papel que desempenha no acontecimento;

b. Condições de sinceridade: o falante deve ser sincero quando agradece, honesto quando propõe, etc;

c. Condições essenciais: o falante é obrigado por uma promessa a empreender a ação indicada. O seu comportamento deve ser coerente.

Naturalmente, essas condições encontram sua validade no plano interno do eixo de comunicação, na personagem-personagem, e não no externo ator-público, ainda que frequentemente (no caso da comédia) assistimos à quebra de tais princípios. Essa quebra é evidente apenas aos olhos do público e não para a personagem que

sertivos: empenham o falante com respeito à verdade das proposições que afirma (ex: "juro que te amo"); 2) diretivos: tentativas por parte do falante de induzir o interlocutor a realizar um ato (ordens, pedidos, perguntas, etc); 3) comissivos: empenham o falante para certa conduta futura (promessas, contratos, etc); 4) expressivos: atos como saudar, agradecer, cumprimentar; 5) declarativos: atos como declarar guerra, designar um candidato, etc.

${ }^{17}$ J. Searle, op. cit., 1969, p. 92.

Cad. Trad., Florianópolis, v. 40, nº 3, p. 300-319, set-dez, 2020. 
a toma como verdade, felizmente, pelos atos ilocucionários realizados por seu interlocutor na cena, dando origem aos "mal-entendidos" que constituem a alma da comédia ${ }^{18}$.

Os atos ilocucionários, por fim, podem apresentar implicações, ao dizer qualquer coisa a mais (ou diferente) daquilo que aparentemente dizem. Na semiótica, as "implicações conversacionais", referentes a uma "leitura entre linhas", ocorrem quando se viola o que Grice ${ }^{19}$ chama de máximas do discurso dramático:

a. Máxima de quantidade: a contribuição deve ser informativa na medida requisitada pela conversação, nem muito longa, nem muito breve;

b. Máxima de qualidade: correspondem às condições de sinceridade enunciadas por Searle;

c. Máxima de relevância: respondem ao imperativo "seja pertinente";

d. Máxima de modo: respondem ao imperativo "seja preciso" (ou seja: "evite a obscuridade, a ambiguidade e a prolixidade" $)^{20}$

Essas máximas regulam implicitamente as contribuições dos participantes no diálogo; são o princípio de decoro indispensável

\footnotetext{
${ }^{18}$ Além da comédia, as peças baseadas no engano dependem do abuso de condições de felicidade dos atos ilocucionários. Um exemplo disso é o engano de Iago no confronto com Otelo. Ao acusar Desdêmona, ele viola as condições preparatórias, uma vez que não tem provas de suas insinuações; viola a máxima de sinceridade porque sabe que o que insinua é falso; viola, por fim, as máximas essenciais por não acreditar completamente que o conselho dado - "look to your wife; observe her well with Cassius" - seja de alguma maneira bom para seu interlocurtor.

${ }^{19}$ H. P. Grice, op. cit., 1967 [1993: 62-64].

${ }^{20}$ Para compreender melhor de que maneira a violação das máximas de Grice realizam implicações conversacionais, ver Elam (op. cit., 1980 [1988: 175 ss.]). Entre outras, é relatado um exemplo de implicação produzida pela violação da terceira máxima ("seja pertinente"): A diz para B "Não vejo sua esposa há muito tempo. Como vai?", C, depois de uma pausa, diz para A: "Que bonita a tua gravata!”. A, pela intervenção desconexa de C, concluirá que sua observação, por algum motivo, é descabida (a mulher de B está morta, fugiu com o leiteiro, etc).
} 
para garantir coerência e continuidade à conversação. Violá-las pode produzir, como já dito, novos significados. Por outro lado, isso pode ser aplicado de maneira sistemática, a fim de anular completamente o decoro interacional, como acontece, por exemplo, no "teatro do absurdo". Por meio da violação, Ionesco cria situações improváveis que deslocam o espectador.

Com relação à função world-creating, em que a linguagem aparece no diálogo dramático, o requisito principal dos atos de fala que constituem um diálogo no interior de uma obra dramática deve ser o do acompanhamento/reiteração. O sistema do turning-talking, ou seja, falar em turno, se realiza em estado puro no diálogo dramático, diferentemente do diálogo que provém de uma conversação cotidiana. Com efeito, se fosse gravada uma conversação entre amigos num bar, notaríamos, ao escutar a fita, como é difícil acompanhar a alternância das intervenções de cada interlocutor e constataríamos a impossibilidade de reproduzir a conversação de maneira compreensível.

Isso se deve ao fato de que as frases de uma conversação cotidiana se produzem por non sequitur, suspensões, incertezas lexicais ou sintáticas, inversões, ilogicidade e, sobretudo, por sobreposições de turnos de fala. Numa conversação dramática, por outro lado, empregada no teatro, no cinema ou na televisão, cada ator espera que seu interlocutor termine de se expressar, antes de dar início à própria intervenção, mantendo um controle rígido sobre o que se chama de floor-apportionment ${ }^{21}$. Isso se deve ao fato de que a conversação não é improvisada, mas representa a transposição cênica de um texto já codificado ${ }^{22}$.

${ }^{21}$ Essa expressão é utilizada por Goffman (Interaction Ritual: Essays on Faceto-Face Behavior. Nova Iorque: Doubleday Anchor, 1967) para indicar a determinação dos turnos de fala.

${ }^{22}$ Sobre isso, se assistirmos a uma das várias ficções produzidas pela televisão, veremos que o floor-apportionment nos diálogos das personagens é claramente definido para produzir, em alguns casos, um efeito de estranhamento até mesmo desconcertante. A ficção, assim, ao se propor como cópia fiel da realidade cotidiana, trai na estrutura do diálogo a sua irredutível natureza "teatral".

Cad. Trad., Florianópolis, v. 40, nº 3, p. 300-319, set-dez, 2020. 
Na tipologia dos textos para traduzir, o texto teatral é um dos mais problemáticos. Logo, é preciso esclarecer o que se entende por tradução teatral. Torop ${ }^{23}$ observa que "tradução" não compreende apenas o material textual interlinguístico ou intralinguístico, mas também o metatextual ${ }^{24}$, o intratextual, o intertextual e o extratextual. A tradução teatral envolve, portanto, mais de uma das tipologias tradutórias acima, levando em consideração, também, a necessária diferença entre a tradução do texto teatral para publicação ou para o palco. Assim, no nível da prática tradutória, se o tradutor trabalhar para uma editora, ele estará mais atento ao texto dramático, dando prioridade, obviamente, não à performance, mas ao cuidado filológico com o texto original, atento ao meio cultural em que o texto foi produzido. A tradução teatral, neste caso, entraria na categoria de tradução literária, ainda que se trate de um texto em que o diálogo prevaleça sobre a narração. No entanto, se o tradutor trabalhar para um diretor ou mesmo no teatro, ele se dedicará ao texto cênico, tornando fundamentais os critérios de performatividade. ${ }^{25}$

Embora a semiologia tenha oferecido diversos aportes ao estudo do teatro, os estudiosos, de maneira geral, concordam ao considerar que o texto dramático seja somente um entre os vários sistemas conectados que constituem o espetáculo, definindo-o como fortemente condicionado pela performatividade. Essa posição diante do texto dramático por parte da semiótica não apenas abriu novas perspectivas nos estudos dramatúrgicos e na prática teatral, como representou, também, um grande impacto no campo dos estudos

${ }^{23}$ P. Torop, Total' nyj perevod, Tartu, Tartu Ülikooli Kirjastus, 1995.

${ }^{24} \mathrm{O}$ termo "metatexto" apresenta dois significados que se regulam entre si: o do resultado de um processo tradutório textual em oposição ao "prototexto" e o de uma imagem geral que o texto representa numa cultura, determinada, para além do texto em si e do aparato crítico que o acompanha.

25 De acordo com Luzi, ("Sulla traduzione teatrale", Texto a fronte, 3, 1990: 97-99) é o palco que decide o valor de uma tradução. Isso não só evidencia e amplifica as soluções felizes, como as infelizes também, repercutindo no trabalho do ator e no alcance de uma boa representação.

Cad. Trad., Florianópolis, v. 40, no 3, p. 300-319, set-dez, 2020. 
da tradução, e a noção de performatividade fez com que alguns tradutólogos reconsiderassem suas posições referentes à tradução do texto teatral.

Nos anos noventa, as teorias nesse campo pareciam polarizadas em torno de dois conceitos: o da performatividade (representação) e o da legibilidade (texto escrito). De um lado, Pavis ${ }^{26}$ observava que a tradução para o palco ia além da tradução interlinguística do texto dramático. Já Bassnett ${ }^{27}$ não partilhava da ideia de performatividade e de uma tradução endereçada à representação, valorizando o texto escrito. A dicotomia performatividade/legibilidade não é de todo convincente. Na prática, não há divisões claras entre uma tradução endereçada à performance e outra à leitura, mas o que existe é um blurring of borderlines ${ }^{28}$. Além disso, a comunicação intercultural depende predominantemente de processos que influenciam não somente a produção da tradução teatral, como também a sua distribuição e recepção por parte de um público plural e versátil. Essas duas posições parecem compartilhar a fragilidade dos aportes prescritivos nos estudos da tradução.

${ }^{26}$ Pavis, P. "Problems of Translation for the Stage: Intercultural and Post-Modern Theatre", em H. Scolnicov, P. Holland (editors), The Play out of Context. Transferring Plays from Culture to Culture. Cambridge: Cambridge University Press, 1989: 25-44.

${ }^{27}$ S. Bassnett, "Translating for the Theatre: Textual Complexities", Essays in Poetics, XV, 1 (1990) 71-83; S. Bassnett, “Translating for the Theatre: The Case against Performability”, TTR, IV, 1 (1990), 99-111. Em realidade, já no início dos anos 80, Bassnett ("The Translator in the Theatre", Theatre Quartely, X, 40, 1981: 37-48) falava do texto dramático como uma unidade verdadeiramente completa apenas quando representada, pois somente na representação é que se realiza todo o seu potencial e, por isso, cabe ao tradutor determinar quais estruturas serão perfomáveis e as traduzir, então, na língua de chegada. Alguns anos depois (S. Bassnett, "Ways through the Labyrinth: Strategies and Methods for Translating Theatre Texts", em T. Hermans (editor), The Manipulation of Literature. Studies in Literary Translation, Londres/Sydney: Croom Helm, 1985: 87-102), sua posição mudou drasticamente a favor do texto escrito, enfatizando a análise das unidades dêiticas e suas funções no interior do texto.

${ }^{28}$ Nikolarea, E. A Communicative Model for Theatre Translation: Version of “Oedipus the King” in English, tese de doutorado, University of Alberta, 1994. 
Com base nas observações de Gostand ${ }^{29}$ sobre o drama como um constante processo de tradução, considera-se agora quais seriam os problemas e/ou as dificuldades que o tradutor de um texto teatral encontra e enfrenta a partir de reflexões tradutórias recentes e dos resultados da semiótica aplicada a esse tipo de texto. A chave de cada tradução, seja literária ou especializada, seria o que Koustas $^{30}$ define como um verdadeiro e singular "dilemme": a escolha entre uma "traduction-assimilation" e o "traduire oui, mais sans traduire". A primeira é uma tradução que assimila o texto na cultura da língua de chegada e a segunda é uma tradução conservadora, isto é, que respeita o texto de partida e a cultura da qual ele faz parte, mas que corre o risco de produzir um texto incompreensível ao destinatário ${ }^{31}$. Portanto, o tradutor deve decidir se assumirá a re-criação dos elementos presentes no texto por meio de outros correspondentes na cultura de recepção ${ }^{32}$. Nesse sentido, Newmark $^{33}$ elaborou uma série de translations rules, distinguindo

${ }^{29}$ Gostand, R. "Verbal and Non-Verbal Communication: Drama as Translation", em Zuber, O. (Ed.). The Languages of Theatre, Problems in the Translation and Transposition of Drama. Toronto: Pergamon Press, 1980: 1-9, aqui p.1 "Drama [...] is a constant process of translation: from original concept to script [...], to producer/ director's interpretation, to contribution by designer and actor / actress, to visual and / or aural images to audience response [...]

${ }^{30}$ Koustas, J. "Traduire ou ne pas traduire le théâtre? L'approche sémiotique”, em Traduction, Terminologie, Rédaction Études sur le texte et ses transformations, Vol. 1, n. 1, $1^{\circ}$ semestre, (1998): 127-128.

${ }^{31} \mathrm{Em}$ outras palavras, podemos dizer que o grau de aceitabilidade do texto é variável segundo a preferência por uma abordagem de adequação ou aceitabilidade. De acordo com a primeira, o texto de chegada, ainda que legível, denota com clareza a própria identidade de metatexto e evidencia sua subordinação quando confrontado com o prototexto. Na segunda, por outro lado, o texto produzido responde ao critério de legibilidade. A tradução "aceitável" se inclina a encobrir a própria identidade do texto traduzido, enquanto a recriação decorre dos cânones da cultura alvo.

${ }^{32}$ Como exemplo, frequentemente acontece que o tradutor, atribuindo certo dialeto à personagem, crie efeitos de ordem burlesca até mesmo onde não são desejados e o espectador acabe tendo uma ideia falseada da obra teatral a que está assistindo. ${ }^{33}$ Newmark, P. La traduzione: problemi e metodi. tradução de F. Frangini. Milão: Garzanti, 1988. 
dois métodos tradutórios: a tradução comunicativa (naturalizante) e a tradução semântica (estrangeirizante).

Entretanto, é precisamente graças aos instrumentos da análise semiótica, ou seja, àqueles mecanismos que num texto produzem o sentido, conferindo-lhe os valores simbólicos das expressões linguísticas, dos gestos, da ambientação, de entonação e ênfase das personagens, etc, que - parafraseando Koustas - algumas obras se prestam mais naturalmente a uma traduction-sans-traduction, enquanto outras a uma traduction-assimilation. É disso que emerge a necessidade do tradutor de elencar uma série de prioridades - a exigência de destacar quais valores no texto de partida devem ser preservados a fim de que o texto traduzido seja adequado ao original. O tradutor deverá, volta e meia, separar as variantes de tradução e, consequentemente, as variáveis, de acordo com o que Schadewaldt ${ }^{34}$ chama de Kunst des richtigen Opsferns. É inevitável que a escolha de uma hierarquia de valores "a preservar" esteja sujeita também ao gosto pessoal do tradutor que, por mais que deseje submeter-se ao texto, não pode se anular completamente nesse processo ${ }^{35}$.

A predominância de uma função com respeito a outra, logo, vem naturalmente imposta ao tradutor pelo tipo e pelo gênero do texto em que está trabalhando. No caso da tradução teatral, os valores estilísticos e formais - fundamentais num texto narrativo -constantemente dão lugar ao que $\mathrm{Hoffman}^{36}$ define como exigência da Bühnenwirksamkeit: a eficácia que o texto deve revelar em cena. Essa última consideração conduz à análise dos problemas e dificuldades encontrados, especificamente, pelo tradutor de teatro. Se é verdade que a tradução teatral é um ato hermenêutico, é verdade também que isso vale para outros tipos de texto. Toda tradução, endereçada

${ }^{34}$ Schadewaldt, W. "Das Problem des Übersetzens”, em H. J. Störig (Ed.), Das Problem des Übersetzens, Darmstadt, Wissenschaftliche Buchgesellschaft, 1973: 223-241.

35 Para uma discussão mais ampla sobre a dimensão subjetiva do tradutor, ver Bertozzi, R. Equivalenza e sapere traduttivo. Milão: LED, 1999: 100-106.

${ }^{36}$ Hoffman, N. Redundanz und Äquivalenz in der literarischen Übersetzung: dargestellt an fünf deutschen Übersetzungen des Hamlet, Tübingen, Niemeyer, 1980. 
ao público de uma cultura diferente (seja por questões cronológicas ou geográficas) da que provém o texto original, revela uma gama de operações de adaptação. Isso vale para referências políticas, históricas, culturais (em alguns casos, linguísticas inclusive $)^{37}$ que, alteradas as condições culturais, não são mais compreensíveis ao público. Tais referências, que na tradução de um texto narrativo podem ser explicadas em notas de rodapé, no texto cênico devem, necessariamente, ser eliminadas ${ }^{38}$. Entre a opção de manter as referências como são, correndo o risco de o texto se tornar obscuro, ou a sua eliminação ou assimilação no seio da cultura de chegada, é mais desejável uma tradução pretendida como compromisso entre o texto de partida e o de chegada. Obviamente, isso é mais fácil de dizer do que fazer, até porque, como vimos, a tradução serve de ponte não só entre duas línguas, mas entre dois universos culturais que, com frequência, não coincidem.

Por fim, podemos observar que, sendo os canais de comunicação no teatro mais numerosos que na página escrita, a abordagem tradutória deve levar em consideração principalmente os sistemas

${ }^{37}$ Duas línguas podem se opor até nas mais íntimas estruturas gramaticais, suponhamos, por exemplo, que numa língua haja flexão de número e na outra não. Às vezes, nem o contexto permitirá esclarecer se é singular ou plural. Numa situação assim, tudo está nas mãos do tradutor e do seu conhecimento. Além disso, é preciso tomar cuidado para não querer reproduzir na língua de chegada todas as particularidades e nuances expressas na língua de partida. Um procedimento assim, de fato, leva a interpretar estruturalmente como equivalentes duas línguas que não o são e produz uma tradução mal-ajambrada e sem naturalidade, senão ambígua. Enfim, não se deve pretender uma equivalência estrutural, mas funcional. Para dar outro exemplo, no caso em que no texto de partida apareçam sotaques regionais ou expressões dialetais, o tradutor não precisa perder tempo, tentando em vão, encontrar um dialeto "correspondente" na língua do texto de chegada, mas precisa, sim, recriar a função que a expressão dialetal continha no original, as conotações "equivalentes", associadas àquele dialeto. Ver Bertozzi, op. cit., (2003): 63.

${ }^{38}$ Um exemplo significativo são as representações modernas das comédias de Aristófanes, ricas em alusões a episódios e personagens políticas da Atenas do século $\mathrm{V}$ a. C. Essas referências, que nas edições das comédias compõem um riquíssimo aparato crítico, são pontualmente eliminadas em cena. 
de significação ${ }^{39}$. A equivalência funcional - que, do nosso ponto de vista, deveria ser o objetivo de toda tradução que não resvale para uma refacção ${ }^{40}$ - não se dá apenas no plano linguístico, mas, também, na ambientação, nos costumes, na recitação, no emprego da iluminação, etc. A condição ideal é (dentro do possível) quando o tradutor e o diretor são a mesma pessoa, "ou, de algum modo, quando a tradução nasce como produto de uma intensa sinergia e colaboração entre tradutor, dramaturgo, diretor e atores" ${ }^{41}$. Em decorrência da raridade dessa condição, o tradutor (que é tradutor de texto escrito; cênico só "em potência”) precisa sempre estar atento ao fato de que a obra que esteja traduzindo tenha, do ponto de vista semiótico, os mesmos significados da original.

A noção de significado exige, contudo, a necessidade de caracterizar o target em que esses significados são traduzidos, desencadeando, assim, o problema do público e a constatação do quanto o universo da recepção é de fundamental importância tanto para o semiólogo quanto para o tradutor. Diferentemente dos outros gêneros textuais, o papel do público no teatro ganha uma estatura de composição bem diversa daquela do leitor individual. Dessa maneira, a função performativa do texto e a sua recepção por parte

${ }^{39}$ De acordo com Veltrusky, (op. cit., (1976): 94-117), a presença de um ator ou de um objeto em cena é o suficiente para modificar os signos. Bogatryrëv (op.cit., 1971) observa que os objetos têm outras qualidades no palco, diferentemente da vida cotidiana. O palco transforma os objetos em signos e sua função cotidiana é anulada em benefício de outras funções significativas na representação; a práxis se torna gesto. O movimento de espantar uma mosca irritante na vida comum (práxis) se transforma em gesto, signo indicativo, no teatro onde pode simbolizar a presença de moscas.

${ }^{40} \mathrm{~A}$ fronteira entre tradução e refacção é muito incerta, nunca clara, já que cada tradução contém elementos do que Koller (Einführung in die Übersetzungswissenschaft, Heidelberg-Wiesbaden, Quelle und Meyer, (1992): 264) define como "schöpferische Bearbeitung" (=elaboração criativa). Trata-se, portanto, de um conceito que traz à luz, inevitavelmente, a pergunta se existe ao menos um grau mínimo de equivalência. (M. Schreiber, Übersetzung und Bearbeitung. Zur Differenzierung und Abgrenzung des Übersetzungsbegriffs, Tübigen, Narr, (1993): 57), um limite mínimo a partir do qual se possa falar de tradução.

${ }^{41}$ Bertozzi, R. op. cit., (2003): 51. 
do público devem ser considerados pelo tradutor como aspectos fundamentais à finalidade de seu trabalho.

\section{Referências}

Austin, J. L.; Urmson, J. O; Sbisà, M. How to Do Things with Words. Cambridge: Harvard University Press, 1962.

Bassnett, Susan. "Translating for the Theatre: Textual Complexities". Essays in Poetics, XV.1 (1990): 71-83.

Bassnett, Susan. "Translating for the Theatre: The Case against Performability". TTR, IV. 1 (1990): 99-111.

Bertozzi, R. "Francesca da Rimini: Semiotica e Testo Teatrale". Francesca da Rimini: Tragedia in cinque atti. Heyse, P. (Ed.). Milano: LED, 2003, pp. 49-68.

Bogatyrëv, P. "Les signes du théâtre”. Poétique, 8, (1971): 517-530.

Eco, U. Trattato di semiotica generale. Milão: Bompiani, 1975.

Elam, K. Elam. The Semiotics of Theatre and Drama. Londres: Methuen, 1980.

Goffman, E. Interaction Ritual: Essays on Face-to-Face Behavior. New York: Doubleday Anchor, 1967.

Gostand, R. "Verbal and Non-Verbal Communication: Drama as Translation". The Languages of Theatre, Problems in the Translation and Transposition of Drama. Zuber-Skerritt, O. (Ed.). Toronto: Pergamon Press, 1980, pp. 1-9. 
Grice, H. P. Logic and Conversation, William James Lectures, Cambridge: Harvard University, 1967.

Hoffman, N. Redundanz und Äquivalenz in der literarischen Übersetzung: dargestellt an fünf deutschen Übersetzungen des Hamlet. Tübingen: Niemeyer, 1980.

Honzl. J. "La mobilité du signe théâtral”. Travail Théâtral, 4 (1971): 5-20

Ingarden, R. The Literary Work of Art: An investigation on the Borderlines of Ontology, Logic and Theory of Literature. With an Appendix on the Functions of Language in the Theatre. Evanston: Northwestern University Press, 1973.

Koller, W. Einführung in die Übersetzungswissenschaft. Heidelberg-Wiesbaden: Quelle und Meyer. (1992): 264

Koustas, J. "Traduire ou ne pas traduire le théâtre? L'approche sémiotique". Traduction, Terminologie, Rédaction Études sur le texte et ses transformations, 1.1, (1998): 127-128.

Kowzan, T. "Le signe au théâtre: introduction à la sémiologie de l'art du spectacle”. Tradução de Simon Pleasance. Diogenes, 16.61, (1968): 59-90.

Kowzan, T. Littérature et spectacle. Califórnia: Mouton, 1975.

Mounin, G. Introduction à la sémiologie. Paris: Les Editions de Minuit, 1970.

Mukarovsky, J. An Attempted Structural Analysis for the Phenomena of the Actor. Praga: Melantrich.1931.

Newmark, P. La traduzione: problemi e metodi. Tradução de F. Frangini. Milão: Garzanti, 1988.

Nikolarea, E. A Communicative Model for Theatre Translation: Version of "Oedipus the King" in English. Edmonton: University of Alberta, 1994. 
Pavis, P. Problems of Translation for the Stage: Intercultural and Post-Modern Theatre. Cambridge: Cambridge University Press, 1989.

Schreiber, M. Übersetzung und Bearbeitung. Zur Differenzierung und Abgrenzung des Übersetzungsbegriffs. Tübigen: Narr, 1993.

Scolnicov. H.; Holland P. The Play out of Context. Transferring Plays from Culture to Culture. Cambridge: Cambridge University Press, 1989.

Ruffini, F. "Semiotica del teatro: ricognizione degli studi", Biblioteca teatrale, 9, (1974): 34-81.

Schadewaldt, W. "Das Problem des Übersetzens”. Das Problem des Übersetzens. Störig H. J. (Ed.). Darmstadt: Wissenschaftliche Buchgesellschaft, 1973, pp. 223-241.

Searle, J. Speech Acts: an Essay in the Philosophy of Language. Cambridge: Cambridge University Press, 1969.

Searle, J. A Taxonomy of Illocutionary acts. Trier: Laut, 1976.

Torop, P. Total' nyj perevod. Tartu: Tartu Ülikooli Kirjastus, 1995.

Veltrusky, J. "Dramatic Text as a Component of Theatre". Semiotics of Art: Prague School Contributions, (1976): 94-117.

Zich, O. Estetika dramatického umění. Praga: Melantrich, 1931.

Recebido em: 10/03/2020

Aceito em: 07/07/2020

Publicado em setembro de 2020

Barbara Delli Castelli. E-mail: b.dellicastelli@unich.it. ORCID: https://orcid. org/0000-0002-4561-0086.

Maria Fernanda Gárbero Email: nandagarbero@gmail.com. ORCID: https://orcid.org/0000-0002-5297-0936. 